\title{
Neurodevelopmental Disorders Commonly Presenting with Sleep Disturbances
}

\author{
Althea Robinson Shelton ${ }^{1}$ (D) Beth Malow ${ }^{1}$ \\ Accepted: 29 November 2020 / Published online: 5 January 2021 \\ (C) The American Society for Experimental NeuroTherapeutics, Inc. 2021
}

\begin{abstract}
There are multiple disorders of neurodevelopment that present with co-occurring sleep disturbances. Many of these neurodevelopmental disorders (NDD) include sleep disturbances in their diagnostic criteria. Neurobiological, genetic, and environmental factors overlap to cause different sleep disorders in individuals with NDD. Caregivers often present reporting either insomnia or hypersomnia, and based on the clinical history and findings from diagnostic tests, an appropriate diagnosis can be made. It is crucial that clinicians understand the different presentations of sleep disturbances in individuals with NDD.
\end{abstract}

Keywords Neurodevelopmental disorders · Autism · Prader Willi syndrome $\cdot$ Rett syndrome · Williams syndrome $\cdot$ Sleep disorders

\section{Introduction}

Sleep disturbances in children with neurodevelopmental disorders (NDD) are extremely prevalent. Sleep problems are significantly higher than in age-matched typically developing children [1], and unlike typically developing individuals, sleep disorders in children with NDD commonly last into adolescence and adulthood [2]. In addition, sleep disturbances are included in the diagnostic criteria for many NDDs. Studies have shown that up to $86 \%$ of individuals with NDD experience sleep problems [3].

There are several disorders of neurodevelopment with prominent sleep disturbances. This review article will focus on disorders presenting with sleep disturbance as a prominent co-occurring problem. We will start by discussing genetic disorders that present with NDD and sleep disturbance and end with discussing sleep problems in autism spectrum disorder (ASD). Table 1 gives a summary of common sleep disturbances/problems seen in each NDD.

Althea Robinson Shelton

althea.a.robinson@vumc.org

1 Department of Neurology, Vanderbilt University Medical Center, 1161 21st Ave South, Medical Center North A-0118, Nashville, TN 37232, USA

\section{Genetic Disorders}

\section{Down Syndrome}

In the USA, the population prevalence of Down syndrome (DS) is approximately 1 in 1500 [4]. It is the most common genetic disorder occurring in about 1 out of 700 live births [5]. The majority of cases occur due to an extra chromosome 21 [6]. However, in 5\% of individuals, 1 copy of chromosome 21 is translocated to another acrocentric chromosome, and, in 2 to $4 \%$ of cases, there is a mosaicism of trisomy [6]. There are now more people with DS living into the 4th, 5th, and 6th decades of life due to an increase in childhood survival [4].

\section{Sleep Disturbances in DS}

Several physical attributes predispose patients with DS to having sleep disturbances. Patients with DS have a smaller bony dimension of the upper airway due to maxillary and midface hypoplasia, as well as relative macroglossia [7]. In addition, patients with DS have varying degrees of hypotonia and this hypotonia predisposes them to airway obstruction and respiratory infections $[8,9]$.

Sleep disorders are often underdiagnosed in children with DS [10]. Patients with DS have been shown to have decreased rapid eye movement sleep (REM) and decreased sleep efficiency $[11,12]$. Compared to typically developing (TD) children, patients with DS are reported to have more excessive 
Table 1 Common sleep disturbances in neurodevelopmental disorders

\begin{tabular}{|c|c|c|c|c|c|}
\hline \multirow{2}{*}{$\begin{array}{l}\text { Neurodevelopmental } \\
\text { disorder }\end{array}$} & \multicolumn{5}{|c|}{ Sleep disturbances } \\
\hline & $\begin{array}{l}\text { Sleep-onset } \\
\text { insomnia }\end{array}$ & $\begin{array}{l}\text { Sleep } \\
\text { maintenance } \\
\text { insomnia }\end{array}$ & $\begin{array}{l}\text { Sleep } \\
\text { disordered } \\
\text { breathing }\end{array}$ & $\begin{array}{l}\text { Excessive } \\
\text { daytime } \\
\text { sleepiness }\end{array}$ & $\begin{array}{l}\text { Nocturnal } \\
\text { seizures }\end{array}$ \\
\hline Angelman syndrome & +++ & ++ & & & ++ \\
\hline Autism & ++ & + & & & + \\
\hline Down syndrome & & + & +++ & ++ & \\
\hline Fragile $\mathrm{X}$ syndrome & +++ & +++ & + & & \\
\hline $\begin{array}{c}\text { Prader-Willi } \\
\text { syndrome }\end{array}$ & & & +++ & +++ & \\
\hline Rett syndrome & ++ & ++ & ++ & & \\
\hline $\begin{array}{l}\text { Smith-Magenis } \\
\text { syndrome }\end{array}$ & +++ & +++ & + & +++ & \\
\hline Williams syndrome & +++ & ++ & & + & \\
\hline
\end{tabular}

daytime sleepiness, fragmented sleep, early morning awakenings, and sleep maintenance insomnia [13]. These are common presenting symptoms in OSA. When compared to controls, adults with DS show lower sleep efficiency and higher prevalence of OSA [14].

Down syndrome patients present primarily with hypersomnia due to untreated and sometimes undertreated OSA. Patients with trisomy 21 are also at risk for central sleep apnea (CSA) and hypoventilation [15]. In the author's experience, CSA and hypoventilation often present as morning headache and/or nausea in addition to hypersomnia. There appears to be more risk for CSA in infancy and an increased risk for OSA as patients get older [15]. Approximately 50 to $80 \%$ of children with DS are affected by OSA [16, 17]. The prevalence of OSA in adults with DS is estimated to be 35 to $42 \%$ [18]. The higher prevalence of OSA is due to the craniofacial and upper airway abnormalities that are associated with trisomy 21 . The severity of OSA increases with comorbidities, such as hypothyroidism and cardiac abnormalities [19].

Untreated OSA has multiple health-related consequences, including impaired cognitive function and increased risks for cardiovascular disease. Some of the cardiovascular consequences of untreated OSA include congestive heart failure, left ventricular hypertrophy, and pulmonary hypertension $[20,21]$. In addition, cor pulmonale and pulmonary hypertension in DS are associated with OSA [21, 22].

Untreated OSA can lead to cognitive dysfunction [23]. Children with OSA often present with hyperactivity, behavioral disruptions, and poor school performance [24-26]. One study showed that children with DS and OSA performed worse on cognitive flexibility tasks than those without OSA [27]. In addition, DS patients with higher obstructive apnea hypopnea indices (oAHI) on PSG have been shown to have reduced visuoperceptual skills [28]. Mood can also be affected in patients with untreated OSA [29]. In adolescents with DS, comorbid depression and OSA have been associated with functional decline [28].

\section{Treatment}

The American Academy of Pediatrics has recommended that at least once in the first 5 years of life, symptoms of OSA, including daytime sleepiness, heavy breathing, snoring, uncommon sleep positions, frequent night awakenings, apneic pauses, and behavior problems, be discussed with parents of children with DS [30]. In addition, every cardiologic follow-up should include screening for OSA. Given the poor correlation between polysomnogram (PSG) results and parental report, all children with DS were recommended to have an overnight PSG by 4 years of age regardless of symptoms [31]. Periodic screening, even after age 4, should be performed.

Adenotonsillectomy is the gold standard first-line treatment for OSA in children [32]. Sleep parameters do improve in patients with DS after adenotonsillectomy [33]. Although adenotonsillectomy will often reduce the oAHI in children with DS, it usually does not normalize it [34]. Thus, repeat PSG 3 months after adenotonsillectomy is necessary. Weight management should also be discussed. In a recent study, obesity was the sole risk factor for severe OSA in patients with DS [35]. If OSA persists, re-evaluation by ENT for possible multilevel upper airway surgery, such as lingual tonsillectomy and possible midline glossectomy, is warranted [36]. If the patient is not a candidate for surgery, treatment with CPAP is an option. CPAP should be first-line treatment for adults with DS and OSA. A more recent technology in the treatment of OSA is the hypoglossal nerve stimulator [37]. Hypoglossal nerve stimulation appears to be an effective and safe treatment alternative in older school age children, teens, and young adults who cannot tolerate CPAP [37, 38]. 


\section{Fragile X Syndrome}

Fragile $\mathrm{X}$ syndrome occurs when there is a CGG expansion of greater than 200 in the fragile X mental retardation (FMR1) gene. It is an X-linked [39] neurodevelopmental disorder. Fragile X (FXS) is one of the most common genetic causes of intellectual disability (ID) [40]. Typically, boys are more affected than girls [41]. A meta-analysis, from 2014, estimated that the prevalence of FXS was 1 in 7000 males and 1 in 11,000 females [42]. There is variation of the phenotypic presentation. In addition to ID (mild to severe), there can be multiple co-occurring conditions, including attention hyperactivity deficit disorder(ADHD), self-injurious behaviors, seizures, anxiety, depression, and language delays [43]. Patients with FXS have a characteristic physical appearance which includes hypotonia, a prominent forehead, an elongated face, high arched palate, protruding ears, and macroorchidism [44]. FXS is the most common monogenic mutation known to cause autism spectrum disorder (ASD) [45].

\section{Sleep Disturbances in FXS}

The literature on sleep disturbances in FXS is growing. Patients with FXS most commonly present with insomnia (difficulty falling and/or staying asleep). However, parasomnias and obstructive sleep apnea (OSA) also present frequently in this population [46]. Studies examining sleep disturbances in patients with FXS have shown the prevalence of sleep disturbance to be 32 to $47 \%$ [47-49]. In a study evaluating a large cohort of 1295 children with FXS using a parental survey, common complaints were difficulty falling asleep (sleep-onset insomnia) and frequent night awakenings (sleep maintenance insomnia) [48]. Studies looking at polysomnogram (PSG) data in this population are limited. However, there have been several studies objectively evaluating sleep using PSG that show that when compared to controls patients with FXS have lower total sleep time, increased wakefulness after sleep onset, increased N1 sleep, and disrupted sleep macrostructure [50-52].

Patients with FXS are at increased risk of developing OSA due to underlying hypotonia along with their facial morphology (high arched palate). The Fragile X Clinical and Research Consortium Database showed a $7 \%$ prevalence of OSA in patients with FXS [41]. FMR permutation carriers that have fragile $\mathrm{X}$ ataxia tremor syndrome have been shown to have an increased prevalence of OSA and are 3.4 times more likely to develop OSA [53].

\section{Treatment}

It is recommended that primary care providers ask about potential sleep problems in children with FXS at every well child visit [41]. In any sleep intervention, concurrent medical/ psychiatric problems and medications should be addressed as they may be the underlying cause of sleep disturbance. This includes underlying sleep disorders such as OSA. Once these have been excluded, behavioral intervention is the firstline treatment of insomnia [54]. Lack of a bedtime routine and/or poor sleep hygiene (daytime and nighttime habits) contribute to sleep disturbance in patients with FXS. Behavioral interventions have been shown to have a positive effect on sleep in patients with FXS [55].

If insomnia persists after behavioral interventions have been implemented, then medication use is warranted. There are no FDA-approved insomnia medications for children in general. There are very few studies evaluating the efficacy of sleep medications in FXS. There have been multiple studies showing the efficacy of melatonin in ASD, and as mentioned above, ASD is commonly co-occurring with FXS. In a randomized control trial, melatonin decreased sleep-onset latency and increased total sleep time [56]. The studies showing the effectiveness of melatonin in ASD used pharmaceutical-grade melatonin in doses ranging from $2 \mathrm{mg}$ to up to $10 \mathrm{mg} / \mathrm{night}, 30$ to $60 \mathrm{~min}$ before bed for its hypnotic effect [57].

A large national survey showed that $61 \%$ of males and $38 \%$ of females were currently taking medication for at least 1 symptom, such as seizures, ADHD, depression [58]. So treatment of insomnia with medication could involve treating cooccurring medical and psychiatric problems [2], for example, using a sedating antidepressant for a patient with depression and insomnia or using a sedating antiepileptic like gabapentin for a patient with insomnia and epilepsy. Behavioral interventions may have to be used concurrently with medications.

\section{Williams Syndrome}

Williams syndrome (WS) is present in 1/7500 individuals. It is caused by a contiguous gene deletion on chromosome 7q11.23. Diagnosis is by chromosomal microarray or fluorescent in situ hybridization. The critical gene appears to be the elastin gene (ELN) [59]. There is multiorgan involvement and it is often recognized due to a diagnosis of congenital heart disease (supravalvular aortic stenosis, peripheral pulmonic stenosis). Additional distinctive features include intellectual disabilities, overfriendliness, anxiety, ADHD, endocrinopathies (hypercalcemia, hypothyroidism, and precocious puberty), failure to thrive, hypotonia, hyper flexibility, and typical facies (e.g., stellate iris pattern) [60].

\section{Sleep Disturbances in WS}

Sleep disturbance is so common in WS, some have argued that it be part of the defining characteristic [61]. Studies have reported the prevalence of sleep disturbances in 65 to $97 \%$ of patients with WS [61, 62]. Parent report-based studies have found that children with WS show resistance to bedtime, sleep 
anxiety, frequent awakenings leading to shorter sleep duration, and excessive daytime somnolence [61] [63]. Adolescents and adults with WS have also been reported to have prolonged sleep onset and reduced sleep efficiency [62]. A correlation between language development scores in children with WS and nighttime sleep duration has been shown. Nighttime sleep duration accounted for a $10 \%$ variance in language development not accounted for by age [64].

There have been several studies using objective data such as actigraphy and polysomnogram (PSG). One recent study, that used both questionnaire and actigraphy data and assessed toddlers with WS from 18 to 30 months found that significant sleep disturbance in WS started as early as 18 months old [65]. Ashworth et al. evaluated sleep parameters in children that were typically developing (TDC), had DS and WS. Patients with WS took twice as long to fall asleep when compared to TDC and children with DS [66]. Difficulty falling asleep and increased restlessness in WS patients compared to controls has been reported [67]. A study of 9 adolescents with WS and 9 controls confirmed these findings and found increased nonrapid eye movement percentage, increased slow-wave sleep, decreased rapid eye movement sleep percentage, increased number of leg movements and irregular sleep cycles [68]. Another study reported increased respiratory-related arousals and increased slow-wave sleep on PSG [67].

\section{Treatment}

Recommendations for management of sleep disturbances in WS mirrors that given for many other NDDS. Although it seems that respiratory parameters are usually within normal limits for children with WS when compared to controls [67], an overnight PSG may still be needed to assess for underlying sleep disorders. Also, adults with WS tend to be overweight and may develop OSA due to weight gain. Medical issues such as reflux should be recognized and treated. Behavior interventions to address sleep hygiene and sleep routine should be implemented. Treatment with melatonin may be beneficial given that studies have reported an abnormal or absent nocturnal melatonin peak. Individuals with WS had increased bedtime cortisol and less pronounced rise in melatonin levels before sleep $[69,70]$. If insomnia does not resolve with behavioral intervention and/or melatonin, treating insomnia with medications that treat co-occurring medical and psychiatric problems is warranted.

\section{Rett Syndrome}

Rett syndrome (RTT) is a severe NDD that is present in 1 in every 10,000 live female births [71]. In its classical form, it is characterized by normal development initially followed by regression in language and motor skills. Repetitive stereotypic hand movements replace purposeful hand use. Additional features include breathing disturbances while awake, bruxism, dysautonomia, abnormal muscle tone, small cold hands and feet, and impaired sleep pattern. Girls may have episodes of screaming and crying and panic-like attacks [71, 72]. Males present with a range of phenotypes ranging from severe neonatal encephalopathy, parkinsonism to severe intellectual disability [72].

Rett syndrome is caused by loss of function mutation in methyl-CpG-binding protein 2 (MeCP2) located on the $\mathrm{X}$ chromosome. MECP2-related disorders include an expanded spectrum including atypical Rett syndrome and a phenotype that includes severe neonatal encephalopathy. Diagnosis is by sequencing and deletion/duplication studies of MECP2 [73] [74]. Along with a mutation of the MECP2, the diagnostic criteria for both typical and atypical RTT require a clear history of regression followed by recovery or stabilization [71].

\section{Sleep Disturbances in RTT}

Impaired sleep pattern is included in the supportive criteria for Rett syndrome [71]. In a large study that included 320 families, $80 \%$ of individuals experienced sleep problems. Individuals had frequent nighttime awakenings, bruxism, and difficulty falling asleep. Age was associated with a decreased prevalence of sleep concerns. Night screaming and night laughing was present in $49 \%$ and $77 \%$ of individuals respectively. These 2 phenomena mainly occurred in individuals with large deletions in MECP2. Treatment with medications was only associated in a $1.7 \%$ reduction in further reported sleep problems [75].

Regression is associated with loss of the occipital dominant rhythm, progression of the slowed background activity, alterations in slow-wave sleep, and a decrease of non-rapid eye movement sleep. Sleep quality overall is poor with studies showing reduced sleep efficiency and an increase in waking after falling asleep [76, 77]. Individuals with RTT commonly have breathing dysfunction while awake. The awake breathing abnormalities are described as alternating hyperpnea followed by apnea which can be associated with cyanosis and at times syncope. One study of the PSG characteristics of Rett syndrome showed hypoventilation, central apnea, and hypoxia during waking in $67 \%$ of girls [76]. Awake breathing disturbances diminish over the lifespan, with $19 \%$ of individuals with RTT experiencing remission for at least 1 year, and some entering remission for over 8 years [78]. Positive airway pressure (PAP) for 1 to $2 \mathrm{~h}$ during waking can help treat daytime respiratory symptoms [79].

The awake breathing disturbances mentioned above often disappear during sleep [78]. However, sleep disordered breathing can still be present. Hagebeuk et al. reported on a case series of 11 pediatric patients with RTT in which the prevalence of obstructive sleep apnea was $54.5 \%$ [80]. A more recent retrospective case series showed that $69.2 \%$ of RTT patients had OSA [81]. Individuals with Rett syndrome may 
be at increased risk of central sleep apnea-hypopnea syndrome associated with hypoventilation. In a study of 13 girls with Rett syndrome compared to 40 healthy controls showed ventilatory impairment during sleep [82].

\section{Treatment}

The typical presentation of both central sleep apnea and obstructive sleep apnea includes respiratory pauses in sleep (apnea) and should prompt referral to a sleep specialist for a PSG. However, other symptoms such as restless sleep, sweating in sleep, and multiple night awakenings can be subtle presentations of sleep apnea. If OSA is present referral to a pediatric otolaryngologist for evaluation for a possible adenotonsillectomy can be considered. PAP therapy (continuous or bilevel) is another option to treat sleep apnea in this population [81]. Melatonin may be helpful for difficulties with sleep onset [83]. In one study, melatonin was the most commonly used medication used to treat sleep disturbances in RTT followed by antiepileptic medications and variants of benzodiazepines [75].

\section{Prader-Willi Syndrome}

Prader-Willi syndrome (PWS) is a multisystem genetic disorder present in approximately $1 / 15,000$ individuals [84]. It is recognized as one of the known leading genetic causes of morbid obesity $[85,86]$. Individuals progress through defined nutritional stages with onset of hyperphagia at approximately age 8 [87]. Hypothalamic dysfunction is likely the cause of appetite dysregulation, hypogonadism, short stature, abnormal control of body temperature, and daytime hypersomnia. Infants have severe hypotonia at birth [84].

PWS is caused by lack of paternal expression of the genes in the region of 15q11.2-q13 [84]. A deletion from the paternal copy of chromosome 15q11.2-q13 is the most common cause and occurs in about $70 \%$ of cases. Maternal uniparental disomy can be detected in approximately $25 \%$ of cases. An imprinting defect is present in $<5 \%$ of cases [84].

\section{Sleep Disturbances in PWS}

Obesity and its subsequent consequences such as OSA and sleep hypoventilation are the major causes of mortality in patients with PWS [88]. Sleep disordered breathing is common in PWS. Central sleep apnea is more common in infancy and it improves with age $[89,90]$. However, starting from age 2, OSA is more common [90]. From 3 to 6 years of age, OSA is reported in approximately $80 \%$ of children with PWS [91]. Abnormalities in ventilatory control are common in PWS. In a large proportion of individuals with PWS, there is blunted or no hypoxic ventilator response. Apnea is one cause of hypoxia and more common in PWS when compared to the general population [92]. Similarly, when exposed to hyperoxia, individuals normally would decrease minute ventilation; however, in PWS, higher concentrations of $\mathrm{O}_{2}$ increased minute ventilation [93].

Hypersomnia can be an incapacitating feature of PWS. In a study of 60 adults with PWS, $67 \%$ reported daytime sleepiness. Narcolepsy was diagnosed in $35 \%$, hypersomnia $12 \%$, and a suggestive, but unclear, diagnosis was present in 53\% [94]. Hypocretin levels in the CSF were noted to be in the intermediate level when compared to individuals diagnosed with narcolepsy. Levels also had a negative correlation with Epworth sleepiness scale scores in the PWS group suggesting low CSF orexin levels may play a role in hypersomnia in PWS [95]. Case reports also suggest an increased incidence of cataplexy in PWS. Of the cases reported in the literature, only $1 / 3$ cases possessed the HLA DR15(DR2) DQB1*0602 haplotype [96]. A hindrance to diagnosis of narcolepsy in PWS is that hypersomnia can be related to untreated OSA due to poor adherence to PAP therapy. According to the International Classification of Sleep Disorders (ICSD-3), other underlying causes of sleep fragmentation, such as OSA, must be treated to diagnose narcolepsy. So, if an individual has untreated/ undertreated OSA, the definitive diagnosis of narcolepsy cannot be made [97].

Excessive daytime sleepiness is associated with an increase in these behavioral disturbances in children and adolescents with PWS [98]. In 70 to $90 \%$ of patients with PWS, a characteristic behavioral profile develops. This behavior often involves tantrums, stubbornness, insistence on sameness, and compulsivity [99]. In addition, attention deficit/hyperactivity (ADHD) symptoms and insistence on sameness are common in PWS [100]. Untreated OSA worsens ADHD symptoms [101]. Thus, in the PWS patient population, untreated OSA and hypersomnia may contribute to irritability and impulsivity of actions worsening behavioral outbursts. A PSG should be considered with any new onset of behavioral concerns [102].

\section{Treatment}

There should be routine sleep surveillance for all children with PWS [102]. Central sleep apnea is common in infancy; if present, treatment with oxygen should be considered [90]. OSA is more common in children, adolescents, and adults with PWS. A recent meta-analysis showed adenotonsillectomy to be safe and effective in children with OSA although there was likely to be residual OSA even after treatment [103]. PAP therapy is an option to treat refractory OSA along with weight management.

Growth hormone therapy is a standard of care for individuals with PWS. It is FDA approved for the treatment of children. Guidelines require PSG prior to the initiation of GH and then 8 to 10 weeks postinitiation [104]. This guideline is related to increased concerns regarding sudden death in those individuals with untreated OSA on growth hormone. 
However, more recent case series suggest there is not an increased risk of death over the baseline increased morbidity and mortality in PWS [105]. There is increased risk of sudden death during the first 9 months of treatment in morbidly obese individuals [106].

Modafinil is an effective treatment in many individuals with hypersomnia in the PWS population. Care should be exercised due to possible increased risk of anxiety and a rare but life-threatening Stevens-Johnson syndrome. In some individuals with PWS, modafinil has helped both behavioral and sleep concerns [107, 108]. Pitolisant, although not yet FDA approved for treatment of hypersomnia in PWS, shows promise has a treatment for hypersomnia in PWS [109].

\section{Angelman Syndrome}

Angelman syndrome (AS) occurs in approximately 1/12,000 to $1 / 24,000$. It is characterized by severe intellectual disability, severe speech impairment, gait ataxia, and tremor of the limbs. Approximately $90 \%$ of patients have seizures. There are also characteristic EEG findings. Individuals feature a happy demeanor that is characterized by inappropriate laughter, excitability, and smiling. Progressive microcephaly is often noted by the age of 2 . Hypotonia may be noted at birth and developmental delays are often noted around 6 months of age [110].

AS is caused by lack of maternal expression of UBE3A. Methylation studies of chromosome 15q11.2-q13 detect $80 \%$ of cases. The most common cause is a deletion on chromosome $15 \mathrm{q} 11.2-\mathrm{q} 13$ (70\%). Paternal uniparental disomy is present in 3\% of cases. An imprinting center defect causes $6 \%$ of cases. Approximately $11 \%$ of cases are due to a mutation in the maternally inherited allele of UBE3A, and these cases have normal methylation studies [111].

\section{Sleep Disturbances in AS}

In the consensus guidelines, an abnormal sleep-wake cycle and diminished need for sleep are associated characteristics [112]. There is a high prevalence of sleep disorders in AS, which is reported to be between 20 and $80 \%$ [112]. Sleep disturbance is more common in individuals with AS when compared to individuals with the same cognitive profile [113]. Studies primarily have focused on parent-reported questionnaires to characterize sleep; the prevalence of sleep disturbance in these studies ranges from 25 to $100 \%$ [114-116]. Sleep problems appear to be more severe in early childhood [116, 117]. In adolescents and adults with AS, sleep disturbances have been shown to improve $[117,118]$. Overall, sleep problems are maximal between the ages of 2 and 9 years $[114,116,118,119]$.

A high proportion of children with AS are reported to have increased sleep latency usually due to difficulties settling (calming down for sleep) [119-121]. The most commonly reported problems are difficulty with sleep initiation, frequent night awakenings, and a decreased need for sleep $[114,115]$. Total sleep times is on average 5 to $6 \mathrm{~h}$ per day. However, daytime sleepiness is not reported [118] which is why "diminished need for sleep" is an associated characteristic. Mouse models show a link between Ube3a imprinting and circadian rhythms. Abnormalities in the circadian rhythm play a role in difficulty settling and falling asleep and the decreased need for sleep [122]. Overall, sleep is not well characterized with large studies conducted with PSGs due to the difficulty in obtaining studies in this population. Polysomnography studies show that the percentage of REM sleep is decreased and that slow-wave sleep may be increased [120, 121]. One PSG study showed periodic leg movements to be present in 7/10 participants [121]. As stated earlier, $70 \%$ of AS cases are caused by the deletion of the 15q11-q13 region of the maternally inherited chromosome 15 [111]. This deletion disrupts the gene that encodes for the B3 subunit of the GABAA receptor. This receptor plays an important role in seizure disorders, motor control, and cognitive processing $[123,124]$. Alterations in the GABAA receptor may cause thalamocortical disruptions that lead to the abnormal sleep patterns in AS [124, 125].

Approximately $90 \%$ of patients with AS present with epileptic seizures; seizures disrupt sleep architecture and alter REM sleep [126]. Sleep, particularly non-rapid eye movement stages, can activate clinical seizures [127]. Given that the majority of children with AS have epilepsy, sleep fragmentation, from seizures, is to be expected [116]. In one study, $69 \%$ of AS patients with epilepsy reported sleep problems. In addition, the severity of seizures correlated with sleep disturbances [128]. The possibility of sleep fragmentation due to overt or subclinical seizures should be in the differential diagnosis in an individual with AS presenting with sleep maintenance insomnia [129].

\section{Treatment}

Poor sleep in children and adolescents with AS increases parental stress, decreasing their parenting abilities [130, 131]. Thus, diagnosing and treating sleep disruption in this population are important. There is a relationship between disruptive behaviors and sleep onset. Targeted treatment to improve sleep environment, sleep hygiene, and parent-child interactions during sleep times improves disruptive behaviors in a sustainable way [131]. Treatment may include a trial of melatonin for help in initially falling asleep. In a recent randomized controlled trial, melatonin significantly improved sleep onset and increased total sleep time when compared to placebo in children with AS. The melatonin dose used ranged from 2.5 to $5 \mathrm{mg}$ [132]. GABA-A receptor agonists, such as benzodiazepines, may be helpful for nocturnal awakenings and seizures. In a recent study, characterizing the sleep habits of 50 patients with AS (children and adults), clonidine, trazadone, and melatonin were the most prescribed sleep aids [133]. Each of these sleep aids were effective in treating 
sleep disturbances in the AS cohort [133]. A retrospective chart review of 8 patients with AS showed that mirtazapine improved sleep onset and decreased nighttime awakenings [134].

\section{Smith-Magenis syndrome}

Smith-Magenis syndrome (SMS) affects 1 in 24,000 individuals but is likely underdiagnosed. The actual prevalence may be closer to 1 in 15,000 [135]. SMS is characterized by developmental delay, intellectual disability, behavioral abnormalities, distinctive facial features that progress with age, and sleep disturbance. Other common features are hypotonia, feeding difficulties, failure to thrive, maladaptive and self-injurious behaviors (often recognized after 18 months of age), sleepiness, and listlessness [136]. Speech delay, short stature, vision problems, and hearing loss are often present [137]. SMS is caused by a deletion of chromosome $17 \mathrm{p} 11.2$ or by a mutation in RAI1. Diagnostic workup most often includes a chromosomal microarray, although FISH analysis can be completed. If the diagnosis is suspected and these studies are negative, molecular genetic testing of RAI1 should be performed [136].

\section{Sleep Disturbances in SMS}

Sleep disturbances present as early as infancy and last into adulthood. Sleep problems in SMS are characterized by fragmented and shortened sleep cycles with frequent nighttime awakenings [137]. When compared to typically developing children and children with ASD, individuals with SMS have more night awakenings and early morning awakenings [138]. Individuals with SMS have more sleep disordered breathing than typically developing children [138]. Characteristics of the disorder are linked to behavioral concerns with more severe sleep disturbances associated with increased severity of behavioral concerns. Delays in speech development correlate to severity of sleep disorders [139]. Sleep disturbances in SMS are likely due to a combination of facial anatomy, obesity-related ventilatory problems, and disturbed melatonin cycle [140]. Individuals with SMS have a shift in their circadian rhythm of melatonin [141, 142]. There is diurnal instead of nocturnal secretion of melatonin. In SMS, melatonin peak time has been shown to be 12 p.m. (compared to 3:30 a.m. in a control group) [143]. Thus, excessive daytime sleepiness is typical.

\section{Treatment}

Sleep disturbance in SMS should be approached by a combination of behavioral intervention and medical management. Behavior interventions to address sleep hygiene and sleep routine should be implemented. Treatment is aimed at inversion of the circadian rhythm such as with beta-blockers in the morning to halt daily melatonin secretion. Melatonin should be given in the evening [144-146]. The addition of a beta-blocker in the daytime may help with challenging behaviors [146].

\section{Autism Spectrum Disorder}

Autism spectrum disorder (ASD) now affects 1 in 40 children [147]. The fifth edition of the Diagnostic and Statistical Manual (DSM-V) combined autism, Asperger's syndrome, and persuasive development disorder into a single diagnosis of ASD (DSM-V). ASD is characterized by impairments in social communication and the presence of restricted and repetitive behavioral patterns [148]. Sleep disturbance commonly co-occurs with ASD. Sleep problems are prevalent across spectrum diagnoses and cognitive levels [149, 150]. Estimates of the prevalence of sleep disturbances in ASD range from 40 to $80 \%$ [151]. Autism symptom severity, gastrointestinal problems, and anxiety have been shown to be the main risk factors for sleep problems [152].

\section{Sleep Disturbance in ASD}

Daily functioning can be impaired due to poor sleep in ASD. Studies show that sleep disturbances in ASD worsen core ASD symptoms, such as presence of repetitive behaviors, poor social interactions, and communication difficulties [153, 154]. A large cohort of over 2000 patients with ASD showed that sleep duration was negatively correlated with core ASD symptoms. Patients with short sleep duration were less likely to develop peer relationships [155]. In one study, patients described as poor sleepers had more difficulties with reciprocal social interactions [153], whereas reduced sleep disturbance has been associated with improved social skills and ability [156]. Another study evaluating a large cohort of patients showed that short sleep duration was associated with more parental reports of obsessive-compulsive disorder, depressive disorder, and attention deficit disorder [155]. Mazurek et al. showed that sleep disturbance in children with ASD had a significant association with irritability, inattention, and physical aggression. Night awakenings (sleep maintenance insomnia) were the sleep issue most strongly associated with behavior problems [157].

Parent-reported sleep problems in ASD range from 40 to $80 \%$ depending on the study $[150,158-160,149,151]$. Insomnia is characterized by difficulty falling asleep and/or maintaining sleep or nonrestorative sleep [153]. Difficulty settling and prolonged sleep onset are common parent complaints (sleep-onset insomnia). In ASD, insomnia presents as sleep-onset delay, or frequent nocturnal awakenings and/or reduced sleep duration [161]. In children with ASD, insomnia is 10 times more frequent than in typically developing children and often persists into adolescence [162]. Studies focusing on parent report show that children with ASD can take several hours to fall asleep $[158,159]$. In addition, multiple 
night awakenings that are prolonged are commonly reported. Parents report awakenings that can last up to $3 \mathrm{~h}$ in which the child will often play or lay in bed laughing or talking [159, 163]. Studies have also shown a reduced total sleep time [164] and more self-report of excessive daytime sleepiness than typically developing peers $[159,164]$. Sleep problems have been shown to persist into adulthood and affect daytime functioning. One study showed that adults with high-functioning autism spectrum disorder (HFASD) had more sleep disturbances and poorer sleep efficiency when compared to neurotypical adults [165]. Objective data on insomnia in ASD is often conducted using actigraphy alone, polysomnography (PSG) alone, or both in combination. An actigraph is a wristwatchlike microcomputer that senses physical motion and generates a signal each time it is moved (accelerated). It is generally placed on the wrist. Estimation of sleep parameters is made from the data collected. Studies using actigraphy have shown prolonged sleep latency, frequent night awakenings, and shorter sleep duration in children with ASD [166, 167]. Studies using PSG have shown low sleep efficiencies, prolonged sleep latency, and night waking [168]. Studies show a decrease in total REM sleep and the density of REM sleep in children with ASD $[150,169]$. When compared to children with developmental delay without ASD, children with ASD have lower REM sleep percentages [170].

\section{Neurobiological Abnormalities in ASD Causing Sleep Disturbance}

Genes that control the circadian rhythm and abnormal melatonin production may be the underlying causes of insomnia in autism spectrum disorder [171, 172]. Mutations affecting gene function in circadian-relevant genes are more frequent in patients with ASD than in controls [173]. Clock gene abnormalities have been hypothesized as a causative factor of ASD [174]. Clock gene abnormalities have been theorized to be the causative factor in social reciprocity deficits and temporal synchrony deficits seen in ASD [172]. Melatonin is an important regulator of the circadian rhythm [175]. It has been postulated that the sleep problems found in ASD may be due to genetic abnormalities associated with melatonin synthesis and melatonin's role in modulating synaptic changes [171]. There are several studies that show a decrease in the amount of melatonin or the major metabolite of melatonin (urinary 6sulfatoxymelatonin) in children and adolescents with ASD compared to controls in the serum, saliva, and/or urine [176-178]. Variations in the genes involved in the melatonin synthesis pathway may increase the risk of ASD. The majority of studies have focused on the acetyl serotonin Omethyltransferase (ASMT) gene $[177,179,180]$. ASMT converts serotonin into melatonin [181]. One study looking specifically at subjects with ASD and sleep-onset delay showed higher variations than previously reported in genes related to the melatonin synthesis pathway, in particular ASMT and CYP1A2 [182]. However, there have been studies that show normal melatonin serum levels [183] and similar base changes in the regulatory regions in both the ASD participants and controls [184]. Thus, a combination of abnormal receptor sites, decreased melatonin production, and increased breakdown may explain insomnia in ASD $[185,186]$.

\section{Treatment}

The American Academy of Neurology recently published new guidelines on the treatment of insomnia in children and adolescents with ASD. The guidelines recommend that medical providers review an individual's medications to evaluate for ones that may contribute to sleep disruption and assess for co-occurring medical and psychiatric conditions that may lead to sleep problems. Medical conditions such as epilepsy, GI issues, and other undiagnosed sleep disorders can cause insomnia. If it is determined that the patient's underlying medical condition is the cause of the sleep problem, it should be addressed. Medications should be adjusted (if safe) if they are leading to insomnia [57]. Behavioral strategies should be the initial focus of treatment. Poor sleep hygiene (daytime and nighttime habits) contributes to sleep disturbance in children with ASD. If behavioral strategies and treatment of cooccurring conditions are unsuccessful, sustained- and prolonged-release melatonin alone or in conjunction with cognitive behavioral therapy is recommended. The studies showing the effectiveness of melatonin used pharmaceutical-grade melatonin in doses ranging from $2 \mathrm{mg}$ up to $10 \mathrm{mg} /$ night, 30 to $60 \mathrm{~min}$ before bed for its hypnotic effect [57]. Using medications that treat a co-occurring condition and that are sedating is an option if melatonin is ineffective. Antidepressants promote sleep by decreasing sleep-onset latency, thus increasing total sleep time [187]. Antiepileptics, such as gabapentin, can help with sleep maintenance insomnia [188].

\section{Medications that Disturb Sleep}

As previously stated, clinicians should evaluate for concurrent medical and psychiatric medications that may influence sleep problems. Sleep disruption is a common side effect of many medications used to treat comorbid conditions (mood disorders, behavior problems, epilepsy, ADHD, etc.) that occur in NDDs. Some medications have activating properties that lead to insomnia (sleep onset and/or sleep maintenance) [189]. Antidepressants can improve or disturb sleep depending on the class of the drug and the amount [189]. Objective studies evaluating PSG data in patients taking selective serotonin reuptake inhibitors (SSRIs) indicate that they generally disrupt sleep continuity [190]. Fluoxetine, a commonly used SSRI, has been shown to decrease total sleep time (TST), increase 
wake time, and increase stage N1 sleep [191]. Both insomnia and somnolence have been reported in patients taking serotonin and norepinephrine reuptake inhibitors (SNRIs) [192]. Venlafaxine, a commonly used SNRI, has been shown to increase wake time and stage N1 sleep [193]. SSRIs and SNRIs have been associated with an increase in restless leg syndrome (RLS) and an increase in periodic limb movements (PLMs) in sleep [194]. Untreated RLS can cause sleep-onset insomnia and excessive PLMs can lead to arousals and awakenings at night. Increased drowsiness has been reported with most antiepileptic medications [189]. However, lamotrigine has been associated with subjective reports of insomnia and a decrease in slow-wave sleep [195]. Both typical and atypical antipsychotics have been associated with subjective reports of insomnia (9 to $24 \%$ of patients) [196] although objective data from PSG studies show a decrease in sleep latency and an increase in TST [196]. Stimulant medications are the primary treatment used in ADHD. Clinical trials and subjective reports indicate an increased incidence of insomnia with the use of stimulants [197]. Medications are often needed to treat cooccurring conditions in NDD; recognizing their potential impact on sleep and adjusting the dose or changing the time the medication is given can decrease sleep disruption.

\section{Conclusion}

In an individual with NDD, who likely has underlying medical conditions, untreated sleep disorders can compound their medical problem. The field of sleep medicine needs more well-designed studies focusing on basic science research to increase our understanding of the underlying neurobiological processes causing sleep disturbances and more randomized controlled clinical trials to find effective medical interventions and medications to treat sleep disorders in the NDD population. Developing behavioral intervention algorithms would help standardize behavioral treatment of sleep disturbance and likely increase the success of these interventions.

Required Author Forms Disclosure forms provided by the authors are available with the online version of this article.

Supplementary Information The online version contains supplementary material available at https://doi.org/10.1007/s13311-020-00982-8.

\section{References}

1. Cotton S, Richdale A. Brief report: parental descriptions of sleep problems in children with autism, Down syndrome, and PraderWilli syndrome. Research in developmental disabilities. 2006;27(2):151-161.
2. Angriman M, Caravale B, Novelli L, Ferri R, Bruni O. Sleep in children with neurodevelopmental disabilities. Neuropediatrics. 2015;46(3):199-210.

3. Didden R, Sigafoos J. A review of the nature and treatment of sleep disorders in individuals with developmental disabilities. Research in developmental disabilities. 2001;22(4):255-72.

4. de Graaf G, Buckley F, Skotko BG. Estimation of the number of people with Down syndrome in the United States. Genetics in medicine : official journal of the American College of Medical Genetics. 2017;19(4):439-447.

5. Parker SE, Mai CT, Canfield MA, et al. Updated national birth prevalence estimates for selected birth defects in the United States, 2004-2006. Birth defects research Part A, Clinical and molecular teratology. 2010;88(12):1008-16.

6. Hassold T, Sherman S. Down syndrome: genetic recombination and the origin of the extra chromosome 21. Clinical genetics. 2000;57(2):95-100.

7. Subramanyam R, Fleck R, McAuliffe J, et al. Upper airway morphology in Down Syndrome patients under dexmedetomidine sedation. Brazilian journal of anesthesiology (Elsevier). 2016;66(4): 388-94.

8. De Lausnay M, Verhulst S, Boel L, Wojciechowski M, Boudewyns A, Van Hoorenbeeck K. The prevalence of lower airway anomalies in children with Down syndrome compared to controls. Pediatric pulmonology. 2020;55(5):1259-1263.

9. Alsubie HS, Rosen D. The evaluation and management of respiratory disease in children with Down syndrome (DS). Paediatric respiratory reviews. 2018;26:49-54.

10. Bassell JL, Phan H, Leu R, Kronk R, Visootsak J. Sleep profiles in children with Down syndrome. American journal of medical genetics Part A. 2015;167a(8):1830-5.

11. Mims M, Thottam PJ, Kitsko D, Shaffer A, Choi S. Characterization of sleep architecture in Down syndrome patients pre and post airway surgery. Cureus. 2017;9(1):e983.

12. Nisbet LC, Phillips NN, Hoban TF, O'Brien LM. Characterization of a sleep architectural phenotype in children with Down syndrome. Sleep \& breathing = Schlaf \& Atmung. 2015;19(3): 1065-1071.

13. Hoffmire CA, Magyar CI, Connolly HV, Fernandez ID, van Wijngaarden E. High prevalence of sleep disorders and associated comorbidities in a community sample of children with Down syndrome. Journal of clinical sleep medicine : JCSM : official publication of the American Academy of Sleep Medicine. 2014;10(4): 411-419.

14. Giménez S, Videla L, Romero S, et al. Prevalence of sleep disorders in adults with Down syndrome: a comparative study of selfreported, actigraphic, and polysomnographic findings. Journal of clinical sleep medicine : JCSM : official publication of the American Academy of Sleep Medicine 2018;14(10):1725-1733.

15. Fan Z, Ahn M, Roth HL, Li L, Vaughn BV. Sleep apnea and hypoventilation in patients with Down syndrome: analysis of 144 polysomnogram studies. Children (Basel, Switzerland). 2017;4(7).

16. de Miguel-Díez J, Villa-Asensi JR, Alvarez-Sala JL. Prevalence of sleep-disordered breathing in children with Down syndrome: polygraphic findings in 108 children. Sleep 2003;26(8):10061009.

17. Dyken ME, Lin-Dyken DC, Poulton S, Zimmerman MB, Sedars E. Prospective polysomnographic analysis of obstructive sleep apnea in down syndrome. Archives of pediatrics \& adolescent medicine 2003;157(7):655-660.

18. Hill EA. Obstructive sleep apnoea/hypopnoea syndrome in adults with Down syndrome. Breathe (Sheffield, England). 2016;12(4): e91-e6.

19. Maris M, Verhulst S, Wojciechowski M, Van de Heyning P, Boudewyns A. Outcome of adenotonsillectomy in children with 
Down syndrome and obstructive sleep apnoea. Archives of disease in childhood 2017;102(4):331-336.

20. Cua CL, Blankenship A, North AL, Hayes J, Nelin LD. Increased incidence of idiopathic persistent pulmonary hypertension in Down syndrome neonates. Pediatric cardiology 2007;28(4):250254.

21. Singer LP, Saenger P. Complications of pediatric obstructive sleep apnea. Otolaryngologic clinics of North America 1990;23(4):665676.

22. Levine OR, Simpser M. Alveolar hypoventilation and cor pulmonale associated with chronic airway obstruction in infants with Down syndrome. Clinical pediatrics 1982;21(1):25-29.

23. Borges JG, Ginani GE, Hachul H, Cintra FD, Tufik S, Pompéia S. Executive functioning in obstructive sleep apnea syndrome patients without comorbidities: focus on the fractionation of executive functions. Journal of clinical and experimental neuropsychology 2013;35(10):1094-1107.

24. Kohler MJ, Lushington K, Kennedy JD. Neurocognitive performance and behavior before and after treatment for sleepdisordered breathing in children. Nature and science of sleep 2010;2:159-185.

25. Sedky K, Bennett DS, Carvalho KS. Attention deficit hyperactivity disorder and sleep disordered breathing in pediatric populations: a meta-analysis. Sleep medicine reviews 2014;18(4):349356.

26. Hunter SJ, Gozal D, Smith DL, Philby MF, Kaylegian J, Kheirandish-Gozal L. Effect of sleep-disordered breathing severity on cognitive performance measures in a large community cohort of young school-aged children. American journal of respiratory and critical care medicine 2016;194(6):739-747.

27. Breslin J, Spanò G, Bootzin R, Anand P, Nadel L, Edgin J. Obstructive sleep apnea syndrome and cognition in Down syndrome. Developmental medicine and child neurology 2014;56(7): 657-664.

28. Andreou G, Galanopoulou C, Gourgoulianis K, Karapetsas A, Molyvdas P. Cognitive status in Down syndrome individuals with sleep disordered breathing deficits (SDB). Brain and cognition 2002;50(1):145-149.

29. Hodges E, Marcus CL, Kim JY, et al. Depressive symptomatology in school-aged children with obstructive sleep apnea syndrome: incidence, demographic factors, and changes following a randomized controlled trial of adenotonsillectomy. Sleep. 2018;41(12).

30. Bull MJ. Health supervision for children with Down syndrome. Pediatrics 2011;128(2):393-406.

31. Goffinski A, Stanley MA, Shepherd N, et al. Obstructive sleep apnea in young infants with Down syndrome evaluated in a Down syndrome specialty clinic. American journal of medical genetics Part A. 2015;167a(2):324-330.

32. Marcus CL, Moore RH, Rosen CL, et al. A randomized trial of adenotonsillectomy for childhood sleep apnea. The New England journal of medicine 2013;368(25):2366-2376.

33. Farhood Z, Isley JW, Ong AA, et al. Adenotonsillectomy outcomes in patients with Down syndrome and obstructive sleep apnea. The Laryngoscope 2017;127(6):1465-1470.

34. Ingram DG, Ruiz AG, Gao D, Friedman NR. Success of tonsillectomy for obstructive sleep apnea in children with Down syndrome. Journal of clinical sleep medicine : JCSM : official publication of the American Academy of Sleep Medicine 2017;13(8): 975-980.

35. Chamseddin BH, Johnson RF, Mitchell RB. Obstructive sleep apnea in children with Down syndrome: demographic, clinical, and polysomnographic features. Otolaryngology-head and neck surgery : official journal of American Academy of Otolaryngology-Head and Neck Surgery 2019;160(1):150-157.

36. Propst EJ, Amin R, Talwar N, et al. Midline posterior glossectomy and lingual tonsillectomy in obese and nonobese children with down syndrome: biomarkers for success. The Laryngoscope 2017;127(3):757-763.

37. Friedman M, Jacobowitz O, Hwang MS, et al. Targeted hypoglossal nerve stimulation for the treatment of obstructive sleep apnea: six-month results. The Laryngoscope 2016;126(11):2618-2623.

38. Caloway CL, Diercks GR, Keamy D, et al. Update on hypoglossal nerve stimulation in children with down syndrome and obstructive sleep apnea. The Laryngoscope 2020;130(4):E263-e7.

39. Hunter JE, Berry-Kravis E, Hipp H, Todd PK. FMR1 Disorders. In: Adam MP, Ardinger HH, Pagon RA, Wallace SE, Bean LJH, Stephens K, et al., editors. GeneReviews(®). Seattle (WA): University of Washington, Seattle Copyright (C) 1993-2020, University of Washington, Seattle. GeneReviews is a registered trademark of the University of Washington, Seattle. All rights reserved; 1993.

40. Hersh JH, Saul RA. Health supervision for children with fragile $\mathrm{X}$ syndrome. Pediatrics 2011;127(5):994-1006.

41. Kidd SA, Lachiewicz A, Barbouth D, et al. Fragile X syndrome: a review of associated medical problems. Pediatrics 2014;134(5): 995-1005.

42. Hunter J, Rivero-Arias O, Angelov A, Kim E, Fotheringham I, Leal J. Epidemiology of fragile $\mathrm{X}$ syndrome: a systematic review and meta-analysis. American journal of medical genetics Part A. 2014;164a(7):1648-1658.

43. Bailey DB, Jr., Raspa M, Olmsted M, Holiday DB. Co-occurring conditions associated with FMR1 gene variations: findings from a national parent survey. American journal of medical genetics Part A. 2008;146a(16):2060-2069.

44. Salcedo-Arellano MJ, Dufour B, McLennan Y, Martinez-Cerdeno V, Hagerman R. Fragile X syndrome and associated disorders: clinical aspects and pathology. Neurobiology of disease 2020;136:104740.

45. McDuffie A, Thurman AJ, Hagerman RJ, Abbeduto L. Symptoms of autism in males with fragile $\mathrm{X}$ syndrome: a comparison to nonsyndromic ASD using current ADI-R scores. Journal of autism and developmental disorders 2015;45(7):1925-1937.

46. Accardo JA, Sutorius. Sleep in children with neurodevelopmental disabilities. 2019.

47. Kronk R, Dahl R, Noll R. Caregiver reports of sleep problems on a convenience sample of children with fragile X syndrome. American journal on intellectual and developmental disabilities 2009;114(6):383-392.

48. Kronk R, Bishop EE, Raspa M, Bickel JO, Mandel DA, Bailey $\mathrm{DB}, \mathrm{Jr}$. Prevalence, nature, and correlates of sleep problems among children with fragile $\mathrm{X}$ syndrome based on a large scale parent survey. Sleep. 2010;33(5):679-687.

49. Symons FJ, Byiers BJ, Raspa M, Bishop E, Bailey DB. Selfinjurious behavior and fragile $\mathrm{X}$ syndrome: findings from the national fragile X survey. American journal on intellectual and developmental disabilities 2010;115(6):473-481.

50. Carotenuto M, Roccella M, Pisani F, et al. Polysomnographic findings in fragile $\mathrm{X}$ syndrome children with EEG abnormalities. Behavioural neurology 2019;2019:5202808.

51. Miano S, Bruni O, Elia M, et al. Sleep phenotypes of intellectual disability: a polysomnographic evaluation in subjects with Down syndrome and fragile-X syndrome. Clinical neurophysiology : official journal of the International Federation of Clinical Neurophysiology 2008;119(6):1242-1247.

52. Ferri R, Del Gracco S, Elia M, Musumeci SA, Pettinato S. Heart rate variability and autonomic function during sleep in fragile $\mathrm{X}$ syndrome. American journal of medical genetics 1999;83(4):296297.

53. Hamlin A, Liu Y, Nguyen DV, Tassone F, Zhang L, Hagerman RJ. Sleep apnea in fragile X premutation carriers with and without FXTAS. American journal of medical genetics Part B, Neuropsychiatric genetics : the official publication of the 
International Society of Psychiatric Genetics. 2011;156b(8):9238.

54. Mindell JA, Owens JA. A clinical guide to pediatric sleep: diagnosis and management of sleep problems 2015.

55. Weiskop S, Richdale A, Matthews J. Behavioural treatment to reduce sleep problems in children with autism or fragile X syndrome. Developmental medicine and child neurology 2005;47(2): 94-104.

56. Wirojanan J, Jacquemont S, Diaz R, et al. The efficacy of melatonin for sleep problems in children with autism, fragile X syndrome, or autism and fragile X syndrome. Journal of clinical sleep medicine : JCSM : official publication of the American Academy of Sleep Medicine 2009;5(2):145-150.

57. Williams Buckley A, Hirtz D, Oskoui M, et al. Practice guideline: treatment for insomnia and disrupted sleep behavior in children and adolescents with autism spectrum disorder: report of the Guideline Development, Dissemination, and Implementation Subcommittee of the American Academy of Neurology. Neurology 2020;94(9):392-404.

58. Bailey DB, Jr., Raspa M, Bishop E, Olmsted M, Mallya UG, Berry-Kravis E. Medication utilization for targeted symptoms in children and adults with fragile $\mathrm{X}$ syndrome: US survey. Journal of developmental and behavioral pediatrics : JDBP 2012;33(1): 62-69.

59. CA M. Williams syndrome. In: Adam MP AH, Pagon RA, et al., editors., editor. Seattle (WA): University of Washington, Seattle; 1999 Apr 9 [Updated 2017 Mar 23] 1993-2020.

60. Martens MA, Wilson SJ, Reutens DC. Research review: Williams syndrome: a critical review of the cognitive, behavioral, and neuroanatomical phenotype. Journal of child psychology and psychiatry, and allied disciplines 2008;49(6):576-608.

61. Annaz D, Hill CM, Ashworth A, Holley S, Karmiloff-Smith A. Characterisation of sleep problems in children with Williams syndrome. Research in developmental disabilities 2011;32(1):164169.

62. Goldman SE, Malow BA, Newman KD, Roof E, Dykens EM. Sleep patterns and daytime sleepiness in adolescents and young adults with Williams syndrome. Journal of intellectual disability research : JIDR 2009;53(2):182-188.

63. Abel EA, Tonnsen BL. Sleep phenotypes in infants and toddlers with neurogenetic syndromes. Sleep medicine 2017;38:130-134.

64. Axelsson EL, Hill CM, Sadeh A, Dimitriou D. Sleep problems and language development in toddlers with Williams syndrome. Research in developmental disabilities 2013;34(11):3988-3996.

65. Gwilliam K, Joyce A, Dimitriou D. Early manifestation of sleep problems in toddlers with Williams syndrome using a mixed method longitudinal approach. Research in developmental disabilities 2020;104:103658.

66. Ashworth M, Palikara O, Van Herwegen J. Comparing parental stress of children with neurodevelopmental disorders: the case of Williams SYNDROME, Down syndrome and autism spectrum disorders. Journal of applied research in intellectual disabilities : JARID 2019;32(5):1047-1057.

67. Mason TB, Arens R, Sharman J, et al. Sleep in children with Williams syndrome. Sleep medicine. 2011;12(9):892-897.

68. Gombos F, Bódizs R, Kovács I. Atypical sleep architecture and altered EEG spectra in Williams syndrome. Journal of intellectual disability research : JIDR. 2011;55(3):255-262.

69. Sniecinska-Cooper AM, Iles RK, Butler SA, Jones H, Bayford R, Dimitriou D. Abnormal secretion of melatonin and cortisol in relation to sleep disturbances in children with Williams syndrome. Sleep medicine. 2015;16(1):94-100.

70. Santoro SD, Giacheti CM, Rossi NF, Campos LM, Pinato L. Correlations between behavior, memory, sleep-wake and melatonin in Williams-Beuren syndrome. Physiology \& behavior. 2016;159:14-19.
71. Neul JL, Kaufmann WE, Glaze DG, et al. Rett syndrome: revised diagnostic criteria and nomenclature. Annals of neurology. 2010;68(6):944-950.

72. Kaur S, Christodoulou J. MECP2 disorders. In: Adam MP, Ardinger HH, Pagon RA, Wallace SE, Bean LJH, Stephens K, et al., editors. GeneReviews(®). Seattle (WA): University of Washington, Seattle Copyright (C) 1993-2020, University of Washington, Seattle. GeneReviews is a registered trademark of the University of Washington, Seattle. All rights reserved.; 1993.

73. Amir RE, Van den Veyver IB, Wan M, Tran CQ, Francke U, Zoghbi HY. Rett syndrome is caused by mutations in X-linked MECP2, encoding methyl-CpG-binding protein 2. Nature genetics. 1999;23(2):185-188.

74. Bienvenu T, Carrié A, de Roux N, et al. MECP2 mutations account for most cases of typical forms of Rett syndrome. Human molecular genetics. 2000;9(9):1377-1384.

75. Wong K, Leonard H, Jacoby P, Ellaway C, Downs J. The trajectories of sleep disturbances in Rett syndrome. Journal of sleep research. 2015;24(2):223-233.

76. Marcus CL, Carroll JL, McColley SA, et al. Polysomnographic characteristics of patients with Rett syndrome. The Journal of pediatrics. 1994;125(2):218-224.

77. Amaddeo A, De Sanctis L, Arroyo JO, Khirani S, Bahi-Buisson N, Fauroux B. Polysomnographic findings in Rett syndrome. European journal of paediatric neurology : EJPN : official journal of the European Paediatric Neurology Society. 2019;23(1):214221.

78. Tarquinio DC, Hou W, Neul JL, et al. The course of awake breathing disturbances across the lifespan in Rett syndrome. Brain \& development. 2018;40(7):515-529.

79. Julu PO, Witt Engerström I, Hansen S, Apartopoulos F, Engerström B. Treating hypoxia in a feeble breather with Rett syndrome. Brain \& development. 2013;35(3):270-273.

80. Hagebeuk EE, Bijlmer RP, Koelman JH, Poll-The BT. Respiratory disturbances in rett syndrome: don't forget to evaluate upper airway obstruction. Journal of child neurology. 2012;27(7): 888-892.

81. Sarber KM, Howard JJM, Dye TJ, Pascoe JE, Simakajornboon N. Sleep-disordered breathing in pediatric patients with Rett syndrome. Journal of clinical sleep medicine : JCSM : official publication of the American Academy of Sleep Medicine. 2019;15(10): 1451-1457.

82. Carotenuto M, Esposito M, D'Aniello A, et al. Polysomnographic findings in Rett syndrome: a case-control study. Sleep \& breathing $=$ Schlaf \& Atmung. 2013;17(1):93-8.

83. McArthur AJ, Budden SS. Sleep dysfunction in Rett syndrome: a trial of exogenous melatonin treatment. Developmental medicine and child neurology. 1998;40(3):186-192.

84. Butler MG, Miller JL, Forster JL. Prader-Willi syndrome - clinical genetics, diagnosis and treatment approaches: an update. Current pediatric reviews. 2019;15(4):207-244.

85. Butler MG. Prader-Willi syndrome: current understanding of cause and diagnosis. American journal of medical genetics. 1990;35(3):319-332.

86. Butler MG. Prader-Willi syndrome: obesity due to genomic imprinting. Current genomics. 2011;12(3):204-215.

87. Miller JL, Lynn CH, Driscoll DC, et al. Nutritional phases in Prader-Willi syndrome. American journal of medical genetics Part A. 2011;155a(5):1040-1049.

88. Proffitt J, Osann K, McManus B, et al. Contributing factors of mortality in Prader-Willi syndrome. American journal of medical genetics Part A. 2019;179(2):196-205.

89. Khayat A, Narang I, Bin-Hasan S, Amin R, Al-Saleh S. Longitudinal evaluation of sleep disordered breathing in infants with Prader-Willi syndrome. Archives of disease in childhood. 2017;102(7):634-638. 
90. Cohen M, Hamilton J, Narang I. Clinically important age-related differences in sleep related disordered breathing in infants and children with Prader-Willi Syndrome. PloS one. 2014;9(6): e101012.

91. Sedky K, Bennett DS, Pumariega A. Prader Willi syndrome and obstructive sleep apnea: co-occurrence in the pediatric population. Journal of clinical sleep medicine : JCSM : official publication of the American Academy of Sleep Medicine. 2014;10(4):403-409.

92. Arens R, Gozal D, Omlin KJ, et al. Hypoxic and hypercapnic ventilatory responses in Prader-Willi syndrome. Journal of applied physiology (Bethesda, Md : 1985). 1994;77(5):2224-30.

93. Gozal D, Arens R, Omlin KJ, Ward SL, Keens TG. Absent peripheral chemosensitivity in Prader-Willi syndrome. Journal of applied physiology (Bethesda, Md : 1985). 1994;77(5):22312236.

94. Ghergan A, Coupaye M, Leu-Semenescu S, et al. Prevalence and phenotype of sleep disorders in 60 adults with Prader-Willi syndrome. Sleep. 2017;40(12).

95. Omokawa M, Ayabe T, Nagai T, et al. Decline of CSF orexin (hypocretin) levels in Prader-Willi syndrome. American journal of medical genetics Part A. 2016;170a(5):1181-1186.

96. Tobias ES, Tolmie JL, Stephenson JB. Cataplexy in the PraderWilli syndrome. Archives of disease in childhood. 2002;87(2): 170 .

97. American Academy of Sleep M. The international classification of sleep disorders 2014.

98. Richdale AL, Cotton S, Hibbit K. Sleep and behaviour disturbance in Prader-Willi syndrome: a questionnaire study. Journal of intellectual disability research : JIDR. 1999;43 ( Pt 5):380-392.

99. Dykens EM, Cassidy SB, King BH. Maladaptive behavior differences in Prader-Willi syndrome due to paternal deletion versus maternal uniparental disomy. American journal of mental retardation : AJMR. 1999;104(1):67-77.

100. Wigren M, Hansen S. ADHD symptoms and insistence on sameness in Prader-Willi syndrome. Journal of intellectual disability research : JIDR. 2005;49(Pt 6):449-456.

101. Gozal D. Sleep-disordered breathing and school performance in children. Pediatrics. 1998;102(3 Pt 1):616-620.

102. Duis J, van Wattum PJ, Scheimann A, Salehi P, Brokamp E, Fairbrother L, et al. A multidisciplinary approach to the clinical management of Prader-Willi syndrome. Molecular genetics \& genomic medicine. 2019;7(3):e514.

103. Lee CH, Hsu WC, Ko JY, Yeh TH, Lin MT, Kang KT. Adenotonsillectomy for the treatment of obstructive sleep apnea in children with Prader-Willi syndrome: a meta-analysis. Otolaryngology-head and neck surgery : official journal of American Academy of Otolaryngology-Head and Neck Surgery. 2020;162(2):168-176.

104. Tauber M, Diene G, Molinas C. Growth hormone treatment for Prader-Willi syndrome. Pediatric endocrinology reviews : PER. 2018;16(Suppl 1):91-99.

105. Tauber M, Diene G, Molinas C, Hébert M. Review of 64 cases of death in children with Prader-Willi syndrome (PWS). American journal of medical genetics Part A. 2008;146a(7):881-7.

106. Craig ME, Cowell CT, Larsson P, et al. Growth hormone treatment and adverse events in Prader-Willi syndrome: data from KIGS (the Pfizer International Growth Database). Clinical endocrinology. 2006;65(2):178-185.

107. De Cock VC, Diene G, Molinas C, et al. Efficacy of modafinil on excessive daytime sleepiness in Prader-Willi syndrome. American journal of medical genetics Part A. 2011;155a(7):1552-1557.

108. Weselake SV, Foulds JL, Couch R, Witmans MB, Rubin D, Haqq AM. Prader-Willi syndrome, excessive daytime sleepiness, and narcoleptic symptoms: a case report. Journal of medical case reports. $2014 ; 8: 127$.
109. Pullen LC, Picone M, Tan L, Johnston C, Stark H. Cognitive improvements in children with Prader-Willi syndrome following pitolisant treatment-patient reports. The journal of pediatric pharmacology and therapeutics : JPPT : the official journal of PPAG. 2019;24(2):166-171.

110. Dagli AI, Mueller J, Williams CA. Angelman syndrome. In: Adam MP, Ardinger HH, Pagon RA, Wallace SE, Bean LJH, Stephens K, et al., editors. GeneReviews $(\circledR)$. Seattle (WA): University of Washington, Seattle Copyright (C) 1993-2020, University of Washington, Seattle. GeneReviews is a registered trademark of the University of Washington, Seattle. All rights reserved.; 1993.

111. Dan B. Angelman syndrome. 2008.

112. Williams CA, Beaudet AL, Clayton-Smith J, et al. Angelman syndrome 2005: updated consensus for diagnostic criteria. American journal of medical genetics Part A. 2006;140(5):413418.

113. Thibert RL, Larson AM, Hsieh DT, Raby AR, Thiele EA. Neurologic manifestations of Angelman syndrome. Pediatric neurology. 2013;48(4):271-279.

114. Didden R, Korzilius H, Smits MG, Curfs LM. Sleep problems in individuals with Angelman syndrome. American journal of mental retardation : AJMR. 2004;109(4):275-284.

115. Walz NC, Beebe D, Byars K. Sleep in individuals with Angelman syndrome: parent perceptions of patterns and problems. American journal of mental retardation : AJMR. 2005;110(4):243-252.

116. Pelc K, Cheron G, Boyd SG, Dan B. Are there distinctive sleep problems in Angelman syndrome? Sleep medicine. 2008;9(4): 434-441.

117. Sueri C, Ferlazzo E, Elia M, et al. Epilepsy and sleep disorders improve in adolescents and adults with Angelman syndrome: a multicenter study on 46 patients. Epilepsy \& behavior : E\&B. 2017:75:225-229.

118. Clayton-Smith J. Clinical research on Angelman syndrome in the United Kingdom: observations on 82 affected individuals. American journal of medical genetics. 1993;46(1):12-15.

119. Bruni O, Ferri R, Vittori E, et al. Sleep architecture and NREM alterations in children and adolescents with Asperger syndrome. Sleep. 2007;30(11):1577-1585.

120. Miano S, Bruni O, Leuzzi V, Elia M, Verrillo E, Ferri R. Sleep polygraphy in Angelman syndrome. Clinical neurophysiology : official journal of the International Federation of Clinical Neurophysiology. 2004;115(4):938-945.

121. Miano S, Bruni O, Elia M, Musumeci SA, Verrillo E, Ferri R. Sleep breathing and periodic leg movement pattern in Angelman Syndrome: a polysomnographic study. Clinical neurophysiology : official journal of the International Federation of Clinical Neurophysiology. 2005;116(11):2685-2692.

122. Shi SQ, Bichell TJ, Ihrie RA, Johnson CH. Ube3a imprinting impairs circadian robustness in Angelman syndrome models. Current biology : CB. 2015;25(5):537-545.

123. DeLorey TM, Handforth A, Anagnostaras SG, et al. Mice lacking the beta3 subunit of the GABAA receptor have the epilepsy phenotype and many of the behavioral characteristics of Angelman syndrome. The Journal of neuroscience : the official journal of the Society for Neuroscience. 1998;18(20):8505-8514.

124. Huntsman MM, Porcello DM, Homanics GE, DeLorey TM, Huguenard JR. Reciprocal inhibitory connections and network synchrony in the mammalian thalamus. Science (New York, NY). 1999;283(5401):541-3.

125. Dan B, Boyd SG. Angelman syndrome reviewed from a neurophysiological perspective. The UBE3A-GABRB3 hypothesis. Neuropediatrics. 2003;34(4):169-176.

126. Nunes ML, Ferri R, Arzimanoglou A, Curzi L, Appel CC, Costa da Costa J. Sleep organization in children with partial refractory epilepsy. Journal of child neurology. 2003;18(11):763-766. 
127. Herman ST, Walczak TS, Bazil CW. Distribution of partial seizures during the sleep-wake cycle: differences by seizure onset site. Neurology. 2001;56(11):1453-1459.

128. Conant KD, Thibert RL, Thiele EA. Epilepsy and the sleep-wake patterns found in Angelman syndrome. Epilepsia. 2009;50(11): 2497-2500.

129. Robinson-Shelton A, Malow BA. Sleep disturbances in neurodevelopmental disorders. Current psychiatry reports. 2016;18(1):6.

130. Goldman SE, Bichell TJ, Surdyka K, Malow BA. Sleep in children and adolescents with Angelman syndrome: association with parent sleep and stress. Journal of intellectual disability research : JIDR. 2012;56(6):600-608.

131. Allen KD, Kuhn BR, DeHaai KA, Wallace DP. Evaluation of a behavioral treatment package to reduce sleep problems in children with Angelman Syndrome. Research in developmental disabilities. 2013;34(1):676-686.

132. Braam W, Didden R, Smits MG, Curfs LM. Melatonin for chronic insomnia in Angelman syndrome: a randomized placebocontrolled trial. Journal of child neurology. 2008;23(6):649-654.

133. Pereira JA, Ravichandran CT, Mullett J, McDougle CJ, Keary CJ. Characterization of sleep habits and medication outcomes for sleep disturbance in children and adults with Angelman syndrome. American journal of medical genetics Part A. 2020.

134. Hanzlik E, Klinger SA, Carson R, Duis J. Mirtazapine for sleep disturbances in Angelman syndrome: a retrospective chart review of 8 pediatric cases. Journal of clinical sleep medicine : JCSM : official publication of the American Academy of Sleep Medicine. 2020;16(4):591-5.

135. Smith AC, Magenis RE, Elsea SH. Overview of Smith-Magenis syndrome. Journal of the Association of Genetic Technologists. 2005;31(4):163-7.

136. Smith ACM, Boyd KE, Brennan C, et al. Smith-Magenis syndrome. In: Adam MP, Ardinger HH, Pagon RA, Wallace SE, Bean LJH, Stephens K, et al., editors. GeneReviews(®). Seattle (WA): University of Washington, Seattle Copyright (c) 1993-2020, University of Washington, Seattle. GeneReviews is a registered trademark of the University of Washington, Seattle. All rights reserved.; 1993.

137. Gropman AL, Duncan WC, Smith AC. Neurologic and developmental features of the Smith-Magenis syndrome (del 17p11.2). Pediatric neurology. 2006;34(5):337-350.

138. Trickett J, Heald M, Oliver C, Richards C. A cross-syndrome cohort comparison of sleep disturbance in children with SmithMagenis syndrome, Angelman syndrome, autism spectrum disorder and tuberous sclerosis complex. Journal of neurodevelopmental disorders. 2018;10(1):9.

139. Poisson A, Nicolas A, Sanlaville D, Cochat P, De Leersnyder H, Rigard C, et al. Smith-Magenis syndrome is an association of behavioral and sleep/wake circadian rhythm disorders. Archives de pediatrie : organe officiel de la Societe francaise de pediatrie. 2015;22(6):638-645.

140. Connor V, Zhao S, Angus R. Non-invasive ventilation for sleepdisordered breathing in Smith-Magenis syndrome. BMJ case reports. 2016;2016.

141. Potocki L, Glaze D, Tan DX, et al. Circadian rhythm abnormalities of melatonin in Smith-Magenis syndrome. Journal of medical genetics. 2000;37(6):428-433.

142. Spruyt K, Braam W, Smits M, Curfs LM. Sleep complaints and the 24-h melatonin level in individuals with Smith-Magenis syndrome: assessment for effective intervention. CNS neuroscience \& therapeutics. 2016;22(11):928-935.

143. De Leersnyder H. Inverted rhythm of melatonin secretion in Smith-Magenis syndrome: from symptoms to treatment. Trends in endocrinology and metabolism: TEM. 2006;17(7):291-298
144. Carpizo R, Martínez A, Mediavilla D, González M, Abad A, Sánchez-Barceló EJ. Smith-Magenis syndrome: a case report of improved sleep after treatment with beta1-adrenergic antagonists and melatonin. The Journal of pediatrics. 2006;149(3):409-411.

145. Van Thillo A, Devriendt K, Willekens D. Sleep disturbances in Smith-Magenis syndrome: treatment with melatonin and betaadrenergic antagonists. Tijdschrift voor psychiatrie. 2010;52(10): 719-723.

146. De Leersnyder H, de Blois MC, Vekemans M, et al. Beta(1)-adrenergic antagonists improve sleep and behavioural disturbances in a circadian disorder, Smith-Magenis syndrome. Journal of medical genetics. 2001;38(9):586-590.

147. Maenner MJ, Shaw KA, Baio J, et al. Prevalence of autism spectrum disorder among children aged 8 years - Autism and Developmental Disabilities Monitoring Network, 11 Sites, United States, 2016. Morbidity and mortality weekly report Surveillance summaries (Washington, DC : 2002). 2020;69(4):112.

148. American Psychiatric A. Diagnostic and statistical manual of mental disorders : DSM-V2013.

149. Allik H, Larsson JO, Smedje H. Sleep patterns of school-age children with Asperger syndrome or high-functioning autism. Journal of autism and developmental disorders. 2006;36(5):585-595.

150. Richdale AL, Schreck KA. Sleep problems in autism spectrum disorders: prevalence, nature, \& possible biopsychosocial aetiologies. Sleep medicine reviews. 2009;13(6):403-411.

151. Souders MC, Mason TB, Valladares O, Bucan M, Levy SE, Mandell DS, et al. Sleep behaviors and sleep quality in children with autism spectrum disorders. Sleep. 2009;32(12):1566-1578.

152. Hollway JA, Aman MG, Butter E. Correlates and risk markers for sleep disturbance in participants of the Autism Treatment Network. Journal of autism and developmental disorders. 2013;43(12):2830-2843.

153. Malow BA, Marzec ML, McGrew SG, Wang L, Henderson LM, Stone WL. Characterizing sleep in children with autism spectrum disorders: a multidimensional approach. Sleep. 2006;29(12):15631571.

154. Cohen S, Conduit R, Lockley SW, Rajaratnam SM, Cornish KM. The relationship between sleep and behavior in autism spectrum disorder (ASD): a review. Journal of neurodevelopmental disorders. 2014;6(1):44.

155. Veatch OJ, Sutcliffe JS, Warren ZE, Keenan BT, Potter MH, Malow BA. Shorter sleep duration is associated with social impairment and comorbidities in ASD. Autism research : official journal of the International Society for Autism Research. 2017;10(7):1221-1238.

156. May T, Cornish K, Conduit R, Rajaratnam SM, Rinehart NJ. Sleep in high-functioning children with autism: longitudinal developmental change and associations with behavior problems. Behavioral sleep medicine. 2015;13(1):2-18.

157. Mazurek MO, Sohl K. Sleep and behavioral problems in children with autism spectrum disorder. Journal of autism and developmental disorders. 2016;46(6):1906-1915.

158. Krakowiak P, Goodlin-Jones B, Hertz-Picciotto I, Croen LA, Hansen RL. Sleep problems in children with autism spectrum disorders, developmental delays, and typical development: a population-based study. Journal of sleep research. 2008;17(2): 197-206.

159. Schreck KA, Mulick JA. Parental report of sleep problems in children with autism. Journal of autism and developmental disorders. 2000;30(2):127-35.

160. Richdale AL, Prior MR. The sleep/wake rhythm in children with autism. European child \& adolescent psychiatry. 1995;4(3):175186.

161. Kotagal S, Broomall E. Sleep in children with autism spectrum disorder. Pediatric neurology. 2012;47(4):242-51. 
162. Sivertsen B, Posserud MB, Gillberg C, Lundervold AJ, Hysing M. Sleep problems in children with autism spectrum problems: a longitudinal population-based study. Autism : the international journal of research and practice. 2012;16(2):139-150.

163. Reynolds AM, Malow BA. Sleep and autism spectrum disorders. Pediatric clinics of North America. 2011;58(3):685-698.

164. Paavonen EJ, Vehkalahti K, Vanhala R, von Wendt L, Nieminenvon Wendt T, Aronen ET. Sleep in children with Asperger syndrome. Journal of autism and developmental disorders. 2008;38(1):41-51.

165. Baker EK, Richdale AL. Sleep patterns in adults with a diagnosis of high-functioning autism spectrum disorder. Sleep. 2015;38(11): 1765-74.

166. Wiggs L, Stores G. Sleep patterns and sleep disorders in children with autistic spectrum disorders: insights using parent report and actigraphy. Developmental medicine and child neurology. 2004;46(6):372-80.

167. Goodlin-Jones B, Tang K, Liu J, Anders TF. Sleep problems, sleepiness and daytime behavior in preschool-age children. Journal of child psychology and psychiatry, and allied disciplines. 2009;50(12):1532-1540.

168. Limoges E, Mottron L, Bolduc C, Berthiaume C, Godbout R. Atypical sleep architecture and the autism phenotype. Brain : a journal of neurology. 2005;128(Pt 5):1049-61.

169. Miano S, Bruni O, Elia M, et al. Sleep in children with autistic spectrum disorder: a questionnaire and polysomnographic study. Sleep medicine. 2007;9(1):64-70.

170. Buckley AW, Rodriguez AJ, Jennison K, et al. Rapid eye movement sleep percentage in children with autism compared with children with developmental delay and typical development. Archives of pediatrics \& adolescent medicine. 2010;164(11): 1032-1037.

171. Bourgeron $\mathrm{T}$. The possible interplay of synaptic and clock genes in autism spectrum disorders. Cold Spring Harbor symposia on quantitative biology. 2007;72:645-654.

172. Wimpory D, Nicholas B, Nash S. Social timing, clock genes and autism: a new hypothesis. Journal of intellectual disability research : JIDR. 2002;46(Pt 4):352-358.

173. Yang Z, Matsumoto A, Nakayama K, et al. Circadian-relevant genes are highly polymorphic in autism spectrum disorder patients. Brain \& development. 2016;38(1):91-99.

174. Siepka SM, Yoo SH, Park J, Lee C, Takahashi JS. Genetics and neurobiology of circadian clocks in mammals. Cold Spring Harbor symposia on quantitative biology. 2007;72:251-259.

175. Rosenwasser AM, Turek FW. Neurobiology of circadian rhythm regulation. Sleep medicine clinics. 2015;10(4):403-412.

176. Tordjman S, Anderson GM, Pichard N, Charbuy H, Touitou Y. Nocturnal excretion of 6-sulphatoxymelatonin in children and adolescents with autistic disorder. Biological psychiatry. 2005;57(2): 134-138.

177. Melke J, Goubran Botros H, Chaste P, et al. Abnormal melatonin synthesis in autism spectrum disorders. Molecular psychiatry. 2008;13(1):90-98.

178. Mulder EJ, Anderson GM, Kemperman RF, OosterlooDuinkerken A, Minderaa RB, Kema IP. Urinary excretion of 5hydroxyindoleacetic acid, serotonin and 6-sulphatoxymelatonin in normoserotonemic and hyperserotonemic autistic individuals. Neuropsychobiology. 2010;61(1):27-32.

179. Pagan C, Delorme R, Callebert J, et al. The serotonin-Nacetylserotonin-melatonin pathway as a biomarker for autism spectrum disorders. Translational psychiatry. 2014;4:e479.
180. Toma C, Rossi M, Sousa I, et al. Is ASMT a susceptibility gene for autism spectrum disorders? A replication study in European populations. Molecular psychiatry. 2007;12(11):977-979.

181. Ackermann K, Stehle JH. Melatonin synthesis in the human pineal gland: advantages, implications, and difficulties. Chronobiology international. 2006;23(1-2):369-379.

182. Veatch OJ, Pendergast JS, Allen MJ, et al. Genetic variation in melatonin pathway enzymes in children with autism spectrum disorder and comorbid sleep onset delay. Journal of autism and developmental disorders. 2015;45(1):100-110.

183. Goldman SE, Adkins KW, Calcutt MW, et al. Melatonin in children with autism spectrum disorders: endogenous and pharmacokinetic profiles in relation to sleep. Journal of autism and developmental disorders. 2014;44(10):2525-2535.

184. Chaste P, Clement N, Mercati O, et al. Identification of pathwaybiased and deleterious melatonin receptor mutants in autism spectrum disorders and in the general population. PloS one. 2010;5(7): e11495.

185. Veatch OJ, Goldman SE, Adkins KW, Malow BA. Melatonin in children with autism spectrum disorders: how does the evidence fit together? Journal of nature and science. 2015;1(7):e125.

186. Souders MC, Zavodny S, Eriksen W, et al. Sleep in children with autism spectrum disorder. Current psychiatry reports. 2017;19(6): 34.

187. McCall C, McCall WV. What is the role of sedating antidepressants, antipsychotics, and anticonvulsants in the management of insomnia? Current psychiatry reports. 2012;14(5):494-502.

188. Robinson AA, Malow BA. Gabapentin shows promise in treating refractory insomnia in children. Journal of child neurology. 2013;28(12):1618-1621.

189. Kryger M, Roth T, Dement WC. Principles and practice of sleep medicine. Philadelphia (PA): Elsevier; 2017.

190. DeMartinis NA, Winokur A. Effects of psychiatric medications on sleep and sleep disorders. CNS \& neurological disorders drug targets. 2007;6(1):17-29.

191. Wichniak A, Wierzbicka A, Walęcka M, Jernajczyk W. Effects of antidepressants on sleep. Current psychiatry reports. 2017;19(9): 63.

192. Cunningham LA, Borison RL, Carman JS, et al. A comparison of venlafaxine, trazodone, and placebo in major depression. Journal of clinical psychopharmacology. 1994;14(2):99-106.

193. Salín-Pascual RJ, Galicia-Polo L, Drucker-Colín R. Sleep changes after 4 consecutive days of venlafaxine administration in normal volunteers. The Journal of clinical psychiatry. 1997;58(8):348350.

194. Rottach KG, Schaner BM, Kirch MH, et al. Restless legs syndrome as side effect of second generation antidepressants. Journal of psychiatric research. 2008;43(1):70-75.

195. Sammaritano M, Sherwin A. Effect of anticonvulsants on sleep. Neurology. 2000;54(5 Suppl 1):S16-24.

196. Krystal AD, Goforth HW, Roth T. Effects of antipsychotic medications on sleep in schizophrenia. International clinical psychopharmacology. 2008;23(3):150-160.

197. Cohen-Zion M, Ancoli-Israel S. Sleep in children with attentiondeficit hyperactivity disorder (ADHD): a review of naturalistic and stimulant intervention studies. Sleep medicine reviews. 2004;8(5): 379-402.

Publisher's Note Springer Nature remains neutral with regard to jurisdictional claims in published maps and institutional affiliations. 